UDC 621.891

\title{
POTENTIAL DIFFERENCE OF METAL MACHINE PARTS METHODOLOGY FOR DETERMINING THE PARAMETERS OF ADHESIONAL PROPERTIES OF MATERIALS ON THE SMC-2 FRICTION MACHINE
}

\author{
Kubich V.I. ${ }^{1}$, Cherneta O.G. ${ }^{2}$, Yurov V.M. ${ }^{3}$ \\ ${ }^{1}$ National University "Zaporizhzhya polytechnic", Zaporizhia, Ukraine, schmirung@gmail.com \\ 2Dniprovsk State technical University, Kamenskoye, Ukraine, ocherneta@gmail.com \\ ${ }^{3}$ E.A. Buketov Karaganda State University, Karaganda, Republic of Kazakhstan, exciton@list.ru
}

\begin{abstract}
The paper develops the idea of the capabilities of a standard machine for testing materials for friction and wear SMC-2 to determine the parameters of the adhesive properties of materials. The results of experimental studies of tribological systems of materials " $40 \mathrm{X}$ - steel 45", "12X2H4 - steel 45", "45XН2MФA - steel 45" are presented. The regularities of the change in the tangential strength of the molecular bond with increasing pressure in the contact, and the coefficients of its hardening during the interaction of the materials under consideration without lubrication are determined. It is shown that in order to reproduce the contact interaction of the operational surfaces of real friction units, it is possible to simulate their shear during deformation provided that full-size fragments placed in regular places of the SMC machine are used. In this case, the equipment of the SMC machine requires minor refinement, which allows us to simulate the shear rate of surfaces as well.
\end{abstract}

Keywords: tribosystem, adhesion, hardness, coefficient of friction, wear, contact

\section{Introduction}

The study of the strength of the adhesive bond between the structural components of the surfaces of parts in tribological conjugations of various engineering objects always seems relevant, since the process of managing both bulk and surface physical and mechanical properties of materials with a wide range of applications is currently not completed. This is evidenced by the scientific results presented in [1-4] and other authors. Along with this, new adhesiometers are being developed and designs of earlier years of production are being improved [5].

Based on the fact that the contact interaction of metal surfaces during the transmission and transformation of movements is carried out with friction losses, which are determined by the molecular and mechanical components, the determination of the parameters of the latter seems to be an actual scientific and applied task. It is especially important to have numerical values of the parameters of adhesive properties directly for the metal surfaces of full-scale operational friction units of machines and mechanisms with reverse movement, i.e. in which there is a shift with a certain speed of movement, when the manifestation of the molecular (adhesive) component of the friction force manages to manifest itself.

The limited information on the manifestation of the parameters of the molecular component of friction - the shear strength of the adhesive bond $\tau_{0}$ and the piezoelectric coefficient $\beta$ of the molecular component for each particular study determines the use of either data previously obtained for similar materials, or the purposeful determination of parameters by modeling shear on smallsized samples in order to increase objectivity and accuracy evaluation of the result. The data obtained seem necessary, first of all, for the predictive assessment of the tribomechanical properties of material tribosystems using mathematical expressions that establish the relationship between the friction coefficient and parameters of the contact microgeometry, adhesion component, hardness, and load during the manifestation of elastic, plastic, elasto-plastic deformation of friction zones interactions. 
Objective -introducing the capabilities of a standard machine for testing materials for friction and wear SMC-2 to determine the parameters of the adhesive properties of materials.

\section{Research methodology}

It is proposed to determine the parameters of the molecular component in accordance with the method of work on the OT-1 adhesio-meter [6] and on a device using a spherical indenter [1], which involve measuring the friction moment Mt during shear - a violation of the frictional bond of spherical surfaces to flat surfaces of samples (plates) and the radius (diameter) of the projection of the print R0 (d).

However, the simulation of the frictional bond violation will be carried out when shifted from the disk relative to the block, made, for example, in the form of a triangle with a cylindrical outer surface, with the corresponding loads (Fig. 1a) with the corresponding modification of the lower shaft drive.

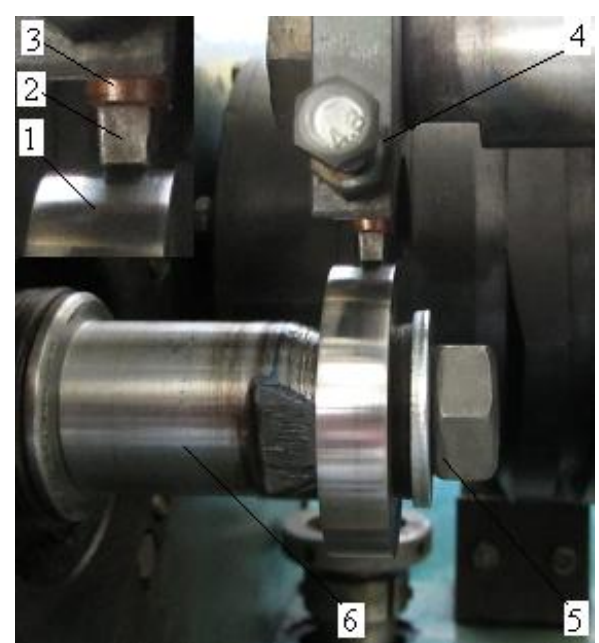

a)

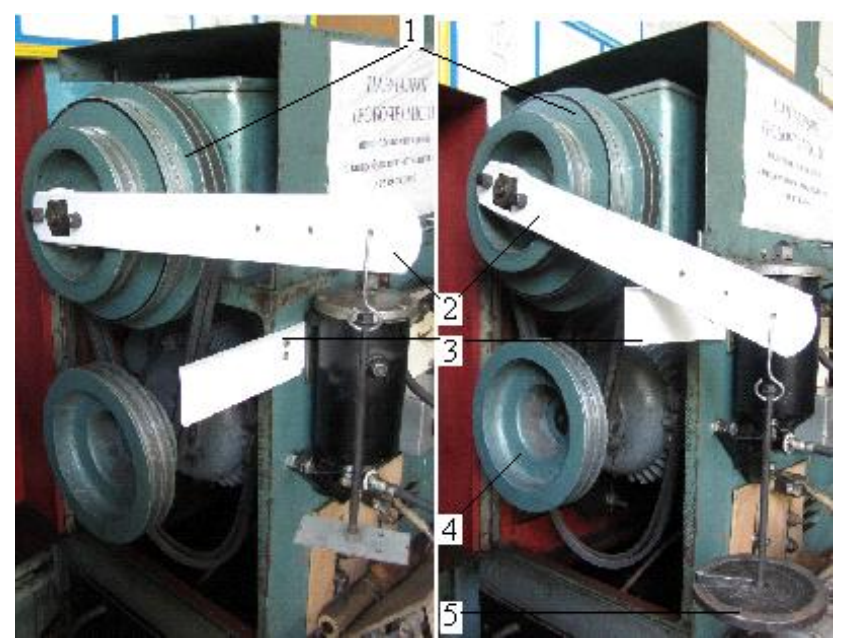

b)

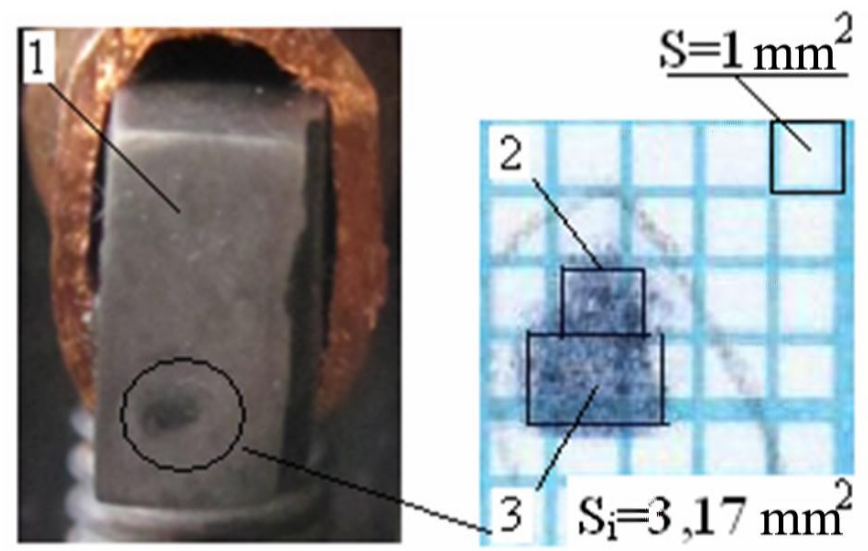

c)

Fig. 1. Methodological support for measuring resistance to displacement during shear: a - contact of model samples: 1 - disk; 2 - block; 3 - additional pad holder; 4 - screws securing the additional holder; 5 - details of the mounting of the disk; 6 - the lower shaft of the friction machine SMC-2; b - angular load drive of the lower shaft: 1 - upper pulley; 2 - cargo lever; 3 - limiter of the stroke of the lever of goods; 4 -

lower pulley; 5 - cargo; in - the imprint of the contact, $\mathrm{N}=280 \mathrm{H}$ : 1 - block; 2,3 - perimeters of the

calculated areas; $\mathrm{c}$ - test sample of material in the mandrel: 1 - fragment of the operating cam of the camshaft of an internal combustion engine; 2,3 - contours of the trace and imprint of wear during shear 
Wherein: - the maximum shear moment is determined by the recorder on the field of the scale tape with a fixed rotation through the angle $\alpha$ with a certain load applied to the lower shaft (Fig. 1 b). The mass of the load will determine the shear rate; - the area of interaction of the friction surfaces is determined by the imprint on graph paper (Fig. $1 \mathrm{c}$ ).

\section{Test procedure}

To test the methodology, the following tribological material systems were used:

- "40X - steel 45";

- "12X2H4 - steel 45";

- "45XH2MFA - steel 45.

Contact interaction was modeled without lubricant. The following samples were used:

- for steel 45 in the form of a triangle (Fig. $1 \mathrm{c}$ ) with a cylindrical outer surface, $4 \mathrm{~mm}$ thick, which was fixed in the mandrel on the fixed shaft of the machine;

- for other metals in the form of a disk with a diameter of $50 \mathrm{~mm}$ and a thickness of $12 \mathrm{~mm}$, which were mounted on the lower shaft of the machine and rotated.

The measurements were carried out in this sequence. Disks of appropriate materials were fixed on the lower shaft of the friction machine. The block was placed in an additional holder, fixed with screws in a standard holder, which was fixed on the upper shaft of the friction machine. Next, the block was pressed with the corresponding force to the disk using the loading screw of the friction machine. The load had values of $140 \mathrm{~N}, 185 \mathrm{~N}, 230 \mathrm{~N}, 280 \mathrm{~N}$. Further, the disk was shifted from its place - it was rotated with the help of weights 5 (Fig. $1 \mathrm{~b}$ ) by a fixed angle $\alpha$. The time for angular displacement also determined the shear rate $-\mathrm{t}_{1}=0.43 \mathrm{~s}$ and $\mathrm{t}_{2}=1 \mathrm{~s}$. The average linear displacement of the disk was $1=4.5 \mathrm{~mm}$. In this case, the recorder in the tribogram recorded the temporary shear resistance by deviation from zero

$$
\tau=\frac{M_{m}}{r \cdot S_{b}},
$$

where $M_{t}$ is the moment of friction during shear, $N \bullet m ; r$ is the radius of the disk, $m$; $S_{b}$ is the imprint area, $\mathrm{mm}^{2}$.

\section{Research results}

A graphical approximation of the averaged data in the form of linear dependencies with inverse extrapolation of the shear resistance of displacements is shown in Fig. 2. Moreover, according to the parameters of the trend lines in Excel, their equations and the reliability of the $\mathrm{R}^{2}$ approximation are determined, the results are shown in Table. 1.

Table 1. Parameters for approximating experimental data for tribological material systems

\begin{tabular}{|l|c|c|c|}
\hline \multicolumn{1}{|c|}{ Parameter } & $\begin{array}{c}\text { «12X2H4 } \\
\text { steel } 45 »\end{array}$ & $\begin{array}{c}\text { 45XH2MФA }- \\
\text { steel } 45 »\end{array}$ & «40X-steel $45 »$ \\
\hline Type of equation & $\tau=0.36 p-13.44$ & $\tau=0.11 p+3.58$ & $\tau=0.28 p-10.27$ \\
\hline Approximation reliability, $R^{2}$ & 0.98 & 0.99 & 0.9 \\
\hline Piezoelectric coefficient,$\beta$ & 0.36 & 0.11 & 0.28 \\
\hline Tangential strength, $\tau_{0}, \mathrm{MPa}$ & $>0$ at $p \approx 37 \mathrm{M \Pi a}$ & 3.58 & $>0$ at $p \approx 36 \mathrm{M \Pi a}$ \\
\hline
\end{tabular}

In accordance with the data shown in Fig. 1, the static friction coefficients (2) are analytically determined - the friction coefficients of the surfaces from which graphical dependencies are constructed (Fig. 3), reflecting the nature of its change.

$$
\mu_{0}=\tau / p \text {. }
$$

An analysis of the results indicates the following. 


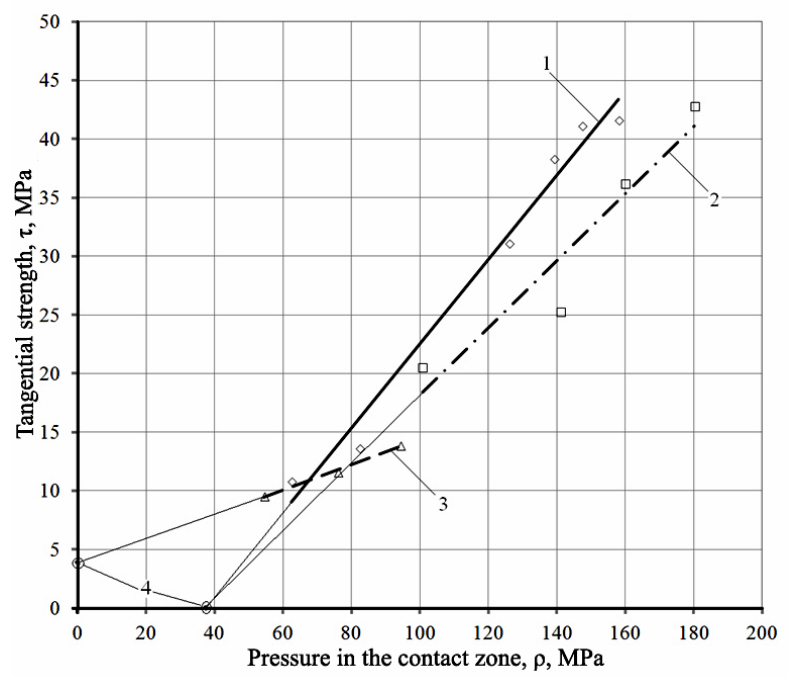

Fig. 2. The dependence of the tangential strength of the adhesive bond of steel 45 on pressure at a shear rate of $10.16 \pm 0.8 \mathrm{~mm} / \mathrm{s}: 1-12 \mathrm{X} 2 \mathrm{H} 4 ; 2$ - 40X; 3 - 45XH2MFA; 4 - points of reverse extrapolation

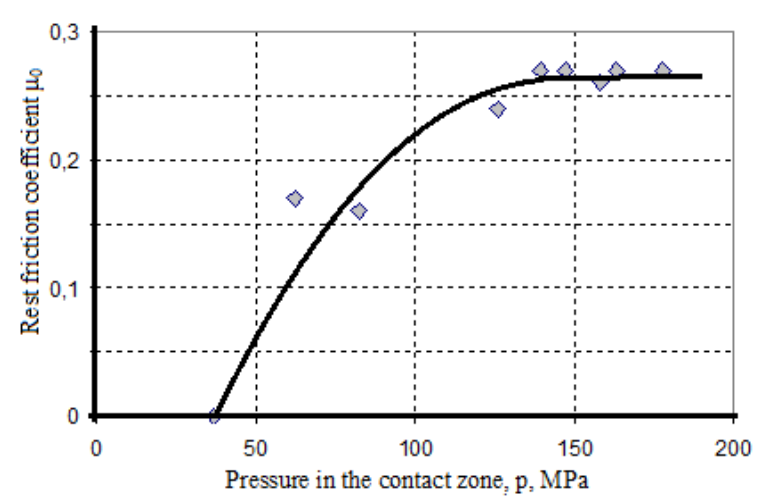

a)

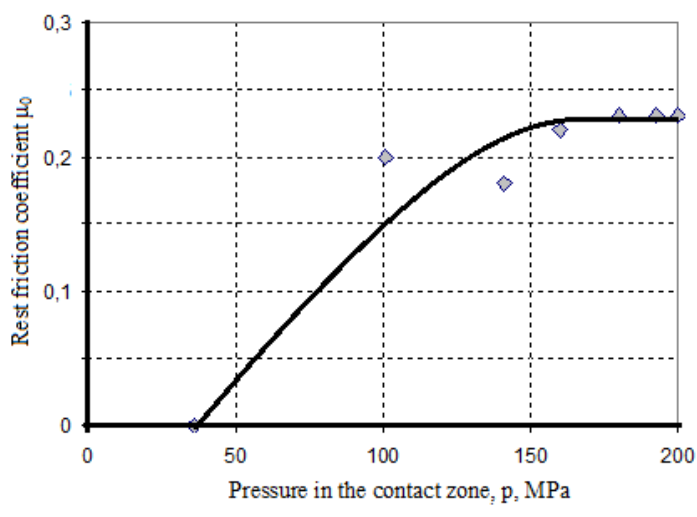

b)

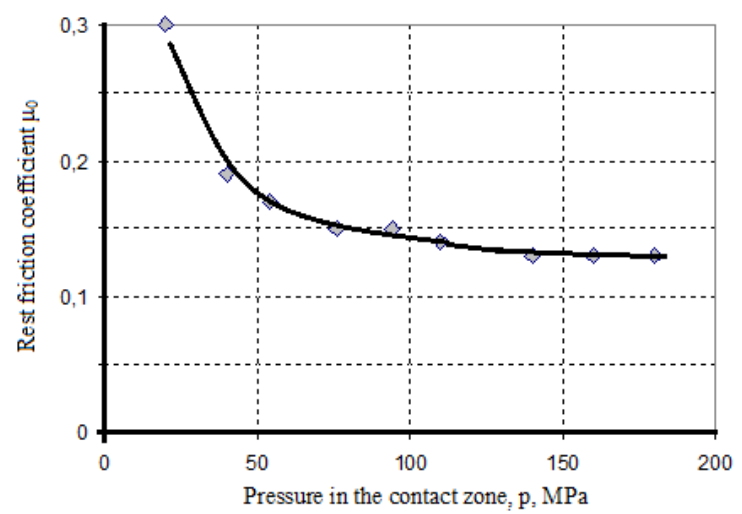

c)

Fig. 3. Dependence of changes in the coefficient of static friction on contact pressure: $\mathrm{a}-1-12 \mathrm{X} 2 \mathrm{H} 4$; b is $40 \mathrm{X}$; $\mathrm{c}-45 \mathrm{XH} 2 \mathrm{MFA}$

The steady-state value of the coefficient of friction manifests itself in the region of high contact pressures:

- for the material system "steel $45-12 \mathrm{X} 2 \mathrm{H} 4 " \mu 0=0.27$ at $\mathrm{p}>140 \mathrm{MPa}$;

- for the material system "steel $45-40 \mathrm{X} " \mu 0=0.23$ at $\mathrm{p}>160 \mathrm{MPa}$;

- for the material system "steel $45-45 X \mathrm{X} 2 \mathrm{MFA} " \mu 0=0.13$ at $\mathrm{p}>130 \mathrm{MPa}$.

Patterns of the nature of the change in the coefficient of friction of rest differ from each other. So for steels $12 \mathrm{X} 2 \mathrm{H} 4$ and $40 \mathrm{X}$, with an increase in contact pressure, the adhesion forces grow to a 
certain value, and then stabilize. For steel 45XH2MFA, on the contrary, decrease with subsequent stabilization. Moreover, for $12 \mathrm{X} 2 \mathrm{H} 4$ steel, the growth rate is higher than for $40 \mathrm{X}$. This can be previously associated with the distribution densities of the microhardnesses of the phases, which are concentrated in the zone of formation of the contour contact areas and the manifestation of molecular interaction forces due to the degree of activation of the surface layers by shear loading.

An analysis of the obtained results indicates the realized possibility of experimentally determining the parameters of adhesive properties, for example, of the considered tribological metal systems. In this case, the numerical values of the parameters do not differ from similar results presented in [1]. Preliminarily obtained results indicate that there are modes of contact interaction with respect to the load, in which when calculating the coefficient of friction it is not advisable to take into account the molecular component, since it begins to appear only from a certain pressure in the contact.

\section{Conclusion}

The proposed approaches for modeling the shear resistance in the contact of small-sized samples depending on normal loading and shear rate with a slight modification of the equipment of the SMC-2 friction machine make it possible to determine the adhesion properties of materials.

The results of experimental studies are presented in accordance with which, on the example of tribological systems of materials " $40 \mathrm{X}$ - steel 45", "12X2H4 - steel 45", "45XН2MФA - steel 45" the ability to determine the parameters of their adhesive properties using the equipment of the friction machine SMTS-2 with little its completion.

The experimental values of the parameters of the molecular component of friction $\tau_{0}$ and $\beta$ obtained on full-scale samples of parts of engineering objects using the proposed approach allow us to obtain more accurate predicted values of the friction and wear characteristics of materials. For example, to determine the coefficient of friction depending on the type of contact and contact conditions (plastic, rough; elastic, rough; single elastic, run-in elastic, etc.), which is one of the parameters of the calculated estimate of the wear rate [7], the number of cycles to fracture of the material. And since the adhesive bond is formed taking into account the contact time, to a greater extent such information is advisable for mechanisms with reverse movement. The lack of objective data on the parameters of the molecular component of the friction force reduces the accuracy of the calculations, which is not excluded when the researchers use reference data obtained either for pure metals or for approximate mechanical properties for those considered in each case.

\section{REFERENCES}

1 Semenov V.I., Shuster L.Sh., Chertovskikh S.V., Raab G.I. Influence of the complex parameter of plastic frictional contact and material structure on the strength of adhesive bonds. Friction and Wear. 2005, Vol. 26, No. 1, pp. 74-79.

2 Dudikina V.V. Adhesion strength of nickel and zinc coatings with a copper base, electrodeposited under external stimulation by laser radiation. Science and transport progress. Newsletter of the Dnipropetrovsk National University of Public Transport, 2013, V.2(44). - P. 83-91

3 Nazarov V.G., Stolyarov V.P., Gagarin M.V. Durability of adhesive rubber-metal adhesion joints for surface fluorinated rubbers. News of higher educational institutions. Problems of printing and publishing. Moscow, MGUP named after Ivan Fedorov. 2013, No.3. - P.45-53

4 Kotomin S.V. Evaluation of the strength of the adhesive bond fiber - thermoplastic matrix by the loop method. Engineering Journal: Science and Innovation, 2015, No. 12. Available at http://engjournal.ru /catalog/msm/pmcm/1426.html

5 Standard Test Method for Adhesion Coating Using Portable Adhesiometers. Designation: D 4541 02. Available at: www. inspector.pro/wp-content/uploads/2016/01/ASTMD4541.pdf

6 Kragelsky I.V., Dobychin M.N., Kombalov V.S. Bases of calculations for friction and wear. Moscow, Mechanical Engineering. 1977, 526 p.

7 Diha O.V. Calculation and experimental methods of control of processes of boundary lubrication of technical tribosystems. Monograph.Khmelnitsky, KhNU, 2018, 197 p. 